\title{
Cellular and Intercellular Homeostasis in Adipose Tissue with Mitochondria-Specific Stress
}

\author{
Min Jeong Choi ${ }^{1}$, Saet-Byel Jung ${ }^{2}$, Joon Young Chang ${ }^{1}$, Minho Shong ${ }^{3}$ \\ ${ }^{1}$ Department of Medical Science, Chungnam National University College of Medicine; ${ }^{2}$ Center for Biomolecular \& Cellular \\ Structure, Institute for Basic Science; ${ }^{3}$ Division of Endocrinology and Metabolism, Department of Internal Medicine, \\ Chungnam National University College of Medicine, Daejeon, Korea
}

Paracrine interactions are imperative for the maintenance of adipose tissue intercellular homeostasis, and intracellular organelle dysfunction results in local and systemic alterations in metabolic homeostasis. It is currently accepted that mitochondrial proteotoxic stress activates the mitochondrial unfolded protein response $\left(\mathrm{UPR}^{\mathrm{mt}}\right)$ in vitro and in vivo. The induction of mitochondrial chaperones and proteases during the UPR ${ }^{\mathrm{mt}}$ is a key cell-autonomous mechanism of mitochondrial quality control. The UPR ${ }^{\mathrm{mt}}$ also affects systemic metabolism through the secretion of cell non-autonomous peptides and cytokines (hereafter, metabokines). Mitochondrial function in adipose tissue plays a pivotal role in whole-body metabolism and human diseases. Despite continuing interest in the role of the UPR ${ }^{\mathrm{mt}}$ and quality control pathways of mitochondria in energy metabolism, studies on the roles of the UPR ${ }^{\mathrm{mt}}$ and metabokines in white adipose tissue are relatively sparse. Here, we describe the role of the UPR ${ }^{\mathrm{mt}}$ in adipose tissue, including adipocytes and resident macrophages, and the interactive roles of cell non-autonomous metabokines, particularly growth differentiation factor 15 , in local adipose cellular homeostasis and systemic energy metabolism.

Keywords: Adipocytes; Mitochondria; Macrophages; Energy metabolism; Unfolded protein response

The Namgok Award is the highest scientific award of the Korean Endocrine Society, and is given to honor an individual who has made excellent contributions to progress in the field of endocrinology and metabolism. The Namgok Award is named after the pen name of Professor Hun Ki Min, who founded the Korean Endocrine Society in 1982. Professor Minho Shong received the Namgok Award at the The 17th AsiaOceania Congress of Endocrinology and the 8th Seoul International Congress of Endocrinology and Metabolism of the Korean Endocrine Society in October 2020.

Received: 12 January 2021, Revised: 26 January 2021,

Accepted: 31 January 2021

\section{Corresponding author: Minho Shong}

Division of Endocrinology and Metabolism, Department of Internal Medicine, Chungnam National University College of Medicine, 266 Munhwa-ro, Jung-gu, Daejeon 35015, Korea

Tel: +82-42-280-7161, Fax: +82-42-280-6990, E-mail: minhos@cnu.ac.kr

\section{INTRODUCTION}

Adipocyte mitochondria are essential organelles for maintaining whole-body metabolism in rodents and humans. Mitochondrial dysfunction in adipocytes has been reported in patients with obesity, insulin resistance, and type 2 diabetes [1]. Although compromised mitochondrial function in adipose tissue may arise from obesity and diabetes, it remains uncertain whether this is a consequence of, or a primary contributor to, the development of insulin resistance. Furthermore, we have a limited understanding of the impact of primary mitochondrial stress in

\section{Copyright $(\odot 2021$ Korean Endocrine Society}

This is an Open Access article distributed under the terms of the Creative Commons Attribution Non-Commercial License (https://creativecommons.org/ licenses/by-nc/4.0/) which permits unrestricted non-commercial use, distribution, and reproduction in any medium, provided the original work is properly cited. 
adipose tissue, and its possible effects on systemic energy homeostasis. Mitochondrial proteins are comprised of mitochondrial DNA (mtDNA)-encoded and nucleus-encoded proteins, and around $99 \%$ of mitochondrial proteins are encoded by the nucleus [2]. Thus, the maintenance of mitonuclear protein balance is important for normal cellular function. Defective mitochondria communicate with the nucleus through retrograde signaling, known as mitonuclear communication, to maintain proper mitochondrial function and organismal homeostasis [3]. Past and recent studies have shown that mitochondrial stress activates the mitochondrial unfolded protein response $\left(\mathrm{UPR}^{\mathrm{mt}}\right)$, which is mediated by cell autonomous and cell non-autonomous pathways [4,5].

Mitochondrial protein homeostasis (proteostasis), which is regulated by chaperones and intrinsic proteases, acts as a key mechanism of mitochondrial quality control [6]. In terms of metabolism, key proteases related to the UPR ${ }^{\mathrm{mt}}$, such as caseinolytic peptidase $\mathrm{P}(\mathrm{ClpP})$ and LON protease (LONP1), have been reported to affect systemic insulin sensitivity and glucose metabolism, respectively [7,8]. In addition to the effects of mitochondrial proteases, knockout (KO) models studying the effects of mitochondrial ribosomal defects have also shown compromised proteostasis and altered systemic metabolism.

Crif1 is a component of the large mitochondrial ribosomal subunit, and its deficiency results in abnormal proteostasis in the mitochondrial matrix of mouse embryonic fibroblasts [9]. In skeletal muscle-specific Crif1 KO mice, oxidative phosphorylation (OxPhos) function and the oxygen consumption rate decreased, but systemic energy homeostasis was maintained by $\mathrm{UPR}^{\mathrm{mt}}$ induction and metabokine production [10]. However, despite studies showing that adipocyte mitochondrial function and quality control are closely related to systemic energy metabolism, there are not many studies on causes of adipocyte-specific OxPhos dysfunction and the effects of metabokines on wholebody metabolism.

Adipose tissue inflammation is considered a major contributor to systemic insulin resistance by inducing pro-inflammatory cytokines secreted from macrophages and cytotoxic T cells [11]. Adipose tissue macrophages (ATMs) can be classified into two groups: classically (M1-like) and alternatively (M2-like)-activated macrophages. Increased macrophage number is characteristic of obese mice and humans [12]. In particular, M1 macrophages, which produce pro-inflammatory cytokines, were found to be elevated in obese individuals. M1 macrophages are characterized by high levels of glycolysis and inducible nitric oxide synthase expression, and secrete tumor necrosis factor alpha and interferon gamma (IFN $\gamma)$ [13]. By contrast, lean individuals had elevated levels of M2 macrophages, which are characterized by high levels of OxPhos, fatty acid oxidation, arginase 1 expression, and secretion of the anti-inflammatory cytokine interleukin 10 (IL-10) [14]. The intact mitochondrial oxidative metabolism of M2 macrophages is a prerequisite for this antiinflammatory phenotype [15]. Therefore, inhibition of oxidative metabolism impairs polarization to the M2-like phenotype, but shifts macrophages towards the M1-like state and leads to obesity, inflammation, and insulin resistance [16]. However, it is unknown whether treatments that can improve the oxidative function of macrophages can reverse insulin resistance and adipose inflammation. In this review, we discuss whether the UP$\mathrm{R}^{\mathrm{mt}}$ and metabokine production caused by lower OxPhos in adipocytes and ATMs regulate systemic energy metabolism and glucose homeostasis.

\section{THE MITOCHONDRIAL UNFOLDED PROTEIN RESPONSE IN ADIPOCYTES IS LINKED TO INCREASED ENERGY EXPENDITURE AND PROTECTION AGAINST DIET-INDUCED OBESITY}

The mitochondria are essential for adipose tissue function, including adipogenesis [17], lipolysis [18], and fatty acid re-esterification [19], which ultimately balances whole body homeostasis. Metabolic challenges such as nutrient excess, aging, and excess free fatty acids lead to mitochondrial dysfunction through the production of mitochondrial reactive oxygen species (ROS) [20]. These lead to reduced mitochondrial biogenesis [21], aggravated inflammation [22], and subsequently promote changes in energy homeostasis and insulin sensitivity [23].

Studies in $o b / o b$ and diabetic mice have shown compromised mitochondrial function in white adipose tissue (WAT), including decreased mitochondrial number, mtDNA quantity, and electron transport chain enzymatic activity [24,25]. This is mirrored in human patients presenting with obesity, insulin resistance, and type 2 diabetes, in whom mitochondrial function-related genes, adenosine triphosphate production, and oxygen consumption are decreased in adipose tissue [26]. A commonality in these mitochondrial stress environments is increased production of ROS, which alters adipogenesis and lipolysis in adipocytes in both mice and humans $[27,28]$. Furthermore, profound adipose tissue mitochondrial dysfunction can lead to lipodystrophy with insulin resistance and hepatic fat accumulation in mice [29]. These studies reveal that adipocyte mitochondrial 
Table 1. Metabolic Phenotypes in Adipocyte-Specific Mitochondrial Dysfunction Models

\begin{tabular}{|c|c|c|c|}
\hline Gene & Name & Phenotype & Reference \\
\hline Tfam (KO) & F-TFKO & $\begin{array}{l}\text { Decreased mtDNA copy quantity and complex I activity } \\
\text { Higher EE and protection from DIO } \\
\text { Improved insulin resistance and hepatosteatosis }\end{array}$ & {$[31]$} \\
\hline Crifl (KO) & AdKO & $\begin{array}{l}\text { Decreased OxPhos complex subunits } \\
\text { Increased UPR } \\
\text { Higher EE and protected from DIO } \\
\text { Improved glucose tolerance and insulin sensitivity }\end{array}$ & {$[32]$} \\
\hline$P g c 1 b(\mathrm{KO})$ & PGC1b-FAT-KO & $\begin{array}{l}\text { Lower mitochondrial oxidative capacity } \\
\text { No difference in glucose homeostasis }\end{array}$ & [30] \\
\hline Pgcla (KO) & FKO & $\begin{array}{l}\text { Reduced OxPhos, FAO, and TCA gene expression } \\
\text { Glucose intolerance, insulin resistance on HFD }\end{array}$ & [33] \\
\hline Ferritin $(\mathrm{O} / \mathrm{E})$ & FtMT-Adip & $\begin{array}{l}\text { Leaner, glucose intolerance, low adiponectin, increased ROS, increased GDF15 and } \\
\text { FGF21, local oxidative stress on DIO }\end{array}$ & {$[34]$} \\
\hline
\end{tabular}

KO, knockout; mtDNA, mitochondrial DNA; EE, energy expenditure; DIO, diet-induced obesity; OxPhos, oxidative phosphorylation; UPR ${ }^{\mathrm{mt}}$, mitochondrial unfolded protein response; FAO, fatty acid oxidation; TCA, tricarboxylic acid; HFD, high fat diet; O/E, overexpression; ROS, reactive oxygen species; GDF15, growth differentiation factor 15; FGF21, fibroblast growth factor 21.

dysfunction is intricately involved in the onset of systemic insulin resistance.

Nonetheless, several studies have questioned the linear relationship between mitochondrial and metabolic dysfunction. A study in adipocyte-specific $P g c l \beta$-deficient mice demonstrated that decreased mitochondrial oxidative capacity in adipocytes was not sufficient for insulin resistance [30]. In addition, Vernochet et al. [31] reported that despite a lower mtDNA quantity in the adipocytes of mitochondrial transcription factor $\mathrm{A} \mathrm{KO}$ mice, the KO mice had higher energy expenditure (EE) and were protected from high fat diet (HFD)-induced obesity and insulin resistance. Further, Bhaskaran et al. [7] demonstrated that the loss of ClpP, which is a mitochondrial quality control protease, protected mice from diet-induced obesity with increased EE and insulin sensitivity. Although a number of investigations have investigated the association between mitochondrial function and systemic insulin sensitivity (Table 1) [30-34], the causes or effects of mitochondrial function in adipocyte and systemic metabolism remain controversial.

Several past and recent studies have discovered that mitochondrial dysfunction causes cellular stress and subsequent metabokine secretion in various species [5,10,35-37]. The UP$\mathrm{R}^{\mathrm{mt}}$, which is conserved from worms to mammals [38], has beneficial effects on whole-body metabolism through cell autonomous and cell non-autonomous pathways [7,10,39]. The cell non-autonomous component of the UPR ${ }^{\mathrm{mt}}$ is mediated by secretory proteins including metabokines, which affect distal organs and requires further mechanistic insight [5]. However, most studies of this phenomenon have used lower organisms [40,41], global $\mathrm{KO}$ mouse models [42], or transgenic mouse models $[43,44]$; thus, the effects of this response in specific tissues remain incompletely understood.

In particular, adipose tissue is a pivotal organ that plays a role in maintaining whole-body homeostasis through energy storage and adipokine secretion [45]. We demonstrated that adipocytespecific activation of the local UPR ${ }^{\mathrm{mt}}$ was protective against the metabolic defects of diet-induced obesity in mice with adipocyte-specific deletion of the Crifl gene (AdKO) [32]. AdKO mice fed an HFD showed improved metabolic phenotype, including decreased fat mass and fatty liver, and increased EE with uncoupling protein 1 (UCP1) induction. The $\mathrm{UPR}^{\mathrm{mt}}$ was induced in adipocytes, and through RNA sequencing analysis, growth differentiation factor 15 (GDF15) was observed to increase dramatically in AdKO mice. Double KO of GDF15 and adipose-specific Crifl abrogated the beneficial metabolic effects seen in AdKO mice, with increased weight gain and decreased EE and UCP1 expression (Fig. 1). This indicates that GDF15 modulates body weight and energy homeostasis in AdKO mice. Studies on global Gdf15 KO have confirmed that GDF15 has a protective effect on obesity [42], but further studies on the mechanisms of $\mathrm{UPR}^{\mathrm{mt}}$ and metabokine secretion are needed. While the evidence is only suggestive for the role of $\mathrm{UPR}^{\mathrm{mt}}$ in metabolic disease in mammals, metabokines such as GDF15 will serve as a useful diagnostic biomarker for human mitochondrial disease, as well as a potential therapeutic modality for metabolic diseases. 


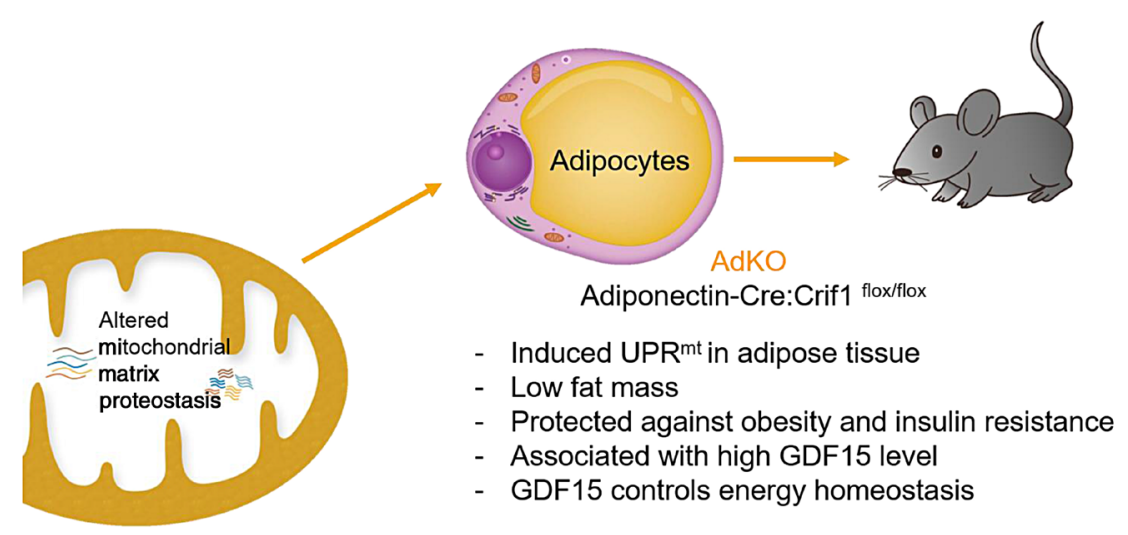

Impaired mitoribosomal function in adipocytes

Fig. 1. Impaired mitoribosomal function in adipocytes is linked to increased energy expenditure and protection against diet-induced obesity and associated with the metabokine growth differentiation factor 15 (GDF15). Adipocyte-specific mitoribosomal defect mice (AdKO), caused by Crifl deficiency, showed altered mitochondrial matrix proteostasis, which resulted in increased levels of chaperones and proteases. AdKO mice showed weight loss and were protected from obesity and insulin resistance. This phenomenon was attributed to increased GDF15 levels in serum and adipose tissue. Thus, GDF15 controlled energy homeostasis and protected from diet-induced obesity in AdKO mice. UPR ${ }^{\mathrm{mt}}$, mitochondrial unfolded protein response.

\section{IMPAIRED MITOCHONDRIAL OXIDATIVE FUNCTION IN ADIPOSE TISSUE MACROPHAGES RESULTS IN ADIPOSE TISSUE INFLAMMATION AND INSULIN RESISTANCE}

Recent investigations have demonstrated that immune cells residing in adipose tissue are involved in the regulation of systemic metabolic homeostasis [46]. Inflammation induced by immune cell infiltration in adipose tissue is a feature of adipose tissue dysfunction. Among the various immune cells, ATMs play a critical role in the adipose tissue microenvironment by determining anti- and pro-inflammatory responses. In obese mice and humans, macrophage infiltration is increased, particularly of M1-polarized macrophages, which are known to secrete proinflammatory cytokines and induce inflammation and systemic insulin resistance [47-49]. Mitochondrial function has been shown to play an important role in macrophage polarization.

Several studies on macrophage mitochondria have been conducted in vitro and in vivo. M1-polarized macrophages induced by lipopolysaccharide and IFN $\gamma$ have low mitochondrial respiration with decreased dependence on the Krebs cycle [50]. On the contrary, M2-polarized macrophages have an intact Krebs cycle, OxPhos, and increased fatty acid oxidation, which is required for the anti-inflammatory response [51]. Studies on the M1-to-M2 macrophage shift have suggested that it is possible to halt the progression of chronic inflammation in adipose tissue $[52,53]$. Although the impaired oxidative function of pro-inflammatory M1 macrophages affecting adipose tissue inflammation and systemic insulin resistance has been extensively studied, it remains unclear whether primary OxPhos deficiency in macrophages causes insulin resistance associated with adipose tissue inflammation.

We demonstrated that a myeloid cell-specific mitoribosomal defect in LysM-Cre mice presented an increased M1-polarized macrophage state in adipose tissue, and the expression of common M2 macrophage genes such as Arg1, Ym1, and GDF15 expression were reduced [54]. Additionally, we showed that reduced mitochondrial oxidative function in macrophages precipitated adipose inflammation, including increased M1 macrophages, and systemic insulin resistance in HFD-fed mice (Fig. 2). It is known that peroxisome proliferator-activated receptor gamma (PPAR $\gamma)$ and signal transducer and activator of transcription 6 activate M2 macrophages by increasing oxidative metabolism and mitochondrial biogenesis [55,56]. M2 macrophages have been linked to an anti-inflammatory response and results in secretion of IL-10, transforming growth factor- $\beta 1$, Ym1, and Fizz1. These proteins are paracrine factors that regulate the adipose tissue environment, and are involved in the determination of the polarization of ATMs. We observed that GDF15 was increased by the Th 2 cytokine IL- 4 and PPAR $\gamma$ agonist rosiglitazone. 


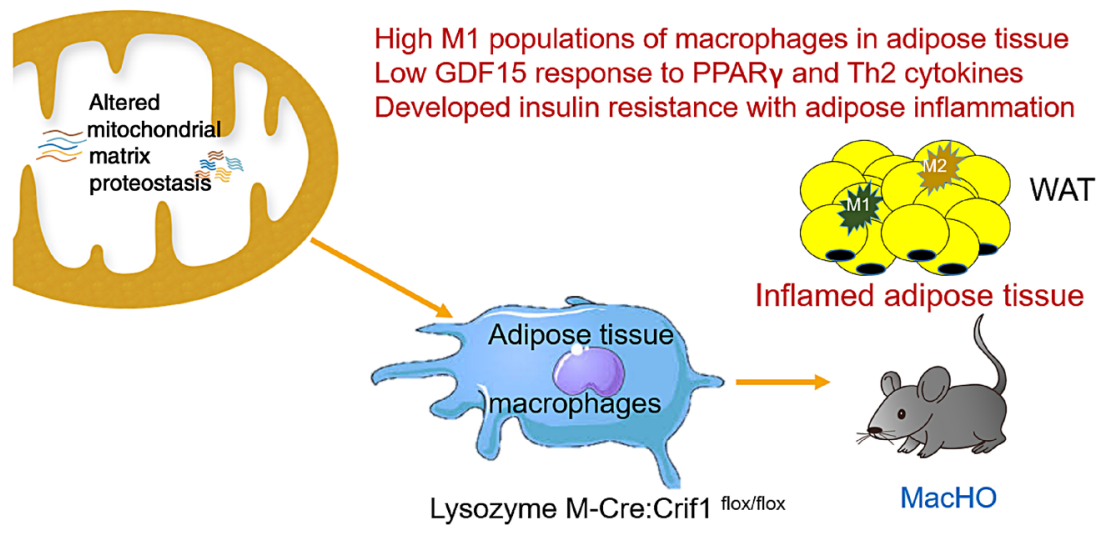

Fig. 2. Impaired mitochondrial oxidative function in adipose tissue macrophages resulting in adipose tissue inflammation and insulin resistance. Mice with a myeloid-specific mitoribosomal defect (MacHO) caused by Crifl deficiency have higher M1 macrophage populations in adipose tissue. This leads to adipose inflammation and insulin resistance in high fat diet-fed mice. The macrophages from MacHO mice showed low growth differentiation factor 15 (GDF15) responses to a peroxisome proliferator-activated receptor gamma (PPAR $\gamma$ ) agonist and T-helper 2 cytokines. Administration of GDF15 in ob/ob and MacHO mice reversed insulin resistance and inflammation, suggesting that GDF15 has an important role in improving the oxidative function of macrophages. WAT, white adipose tissue.

In macrophages, GDF15 treatment results in increased mitochondrial respiration and increased expression of genes related with fatty acid oxidation. By observing the increase in respiration, palmitate oxidation, and fatty acid oxidation-related gene expression in macrophages treated with GDF15, it can be seen that GDF15 induces the shift of the macrophage phenotype by improving oxidative function. Furthermore, it was observed that M2 polarization was not induced in macrophages from GDF15 KO mice, even with IL-4 treatment, and glucose tolerance was impaired by adoptive transfer of bone marrow-derived macrophages from GDF15 KO mice. These results support the role of GDF15 as a regulator of M2 macrophage polarization, indicating that GDF15 is a protein that protects against WAT inflammation. The beneficial effects of GDF15 were further demonstrated by several studies. Upregulated GDF15 has a protective role in advanced atherosclerosis, macrophage accumulation, and apolipoprotein E-deficient mice [57,58]. Moreover, GDF15 transgenic mice showed resistance to diet-induced obesity and increased insulin sensitivity with lower NLR family pyrin domain containing 3 (NLRP3) inflammasome activity in adipose tissue [59], verifying the role of GDF15 in controlling macrophage-mediated adipose inflammation.

Collectively, GDF15 can modulate the adipose tissue immune environment by increasing the oxidative function of macrophages and shifting the polarization to M2-like macrophages. Thus, it can be concluded that GDF15 has both an autocrine and paracrine effect, which can improve systemic metabolic homeostasis.

\section{THE METABOKINE GDF15 COORDINATES CELLULAR AND INTERCELLULAR HOMEOSTASIS IN ADIPOSE TISSUE}

The concept of a mitokine was initially suggested in a Caenorhabditis elegans model, where mitochondrial dysfunction in the brain triggered $\mathrm{UPR}^{\mathrm{mt}}$ activation non-autonomously in gut cells, and was mediated by an unknown factor that was termed a mitokine [5]. It is known that mitokines are secreted from tissues with primary mitochondrial dysfunction, but in the complex mammalian system, a mitokine can be defined as a metabokine capable of controlling systemic metabolism by peripheral and central nervous system pathways $[60,61]$.

While FGF21 is also considered as a major metabokine, it has already been discussed extensively by Geng et al. [60], and the present article will focus on the metabokine GDF15. GDF15 has been studied for its role in models of cancer [62], aging [63], longevity [64], and mitochondrial dysfunction [65]. The expression of GDF15 was observed in mouse and human adipose tissue, and was found to be secreted from adipocytes, suggesting a paracrine role in the modulation of adipose tissue function and body fat mass [66]. We screened possible metabokine candidates in the adipose tissue of AdKO mice, and showed that 


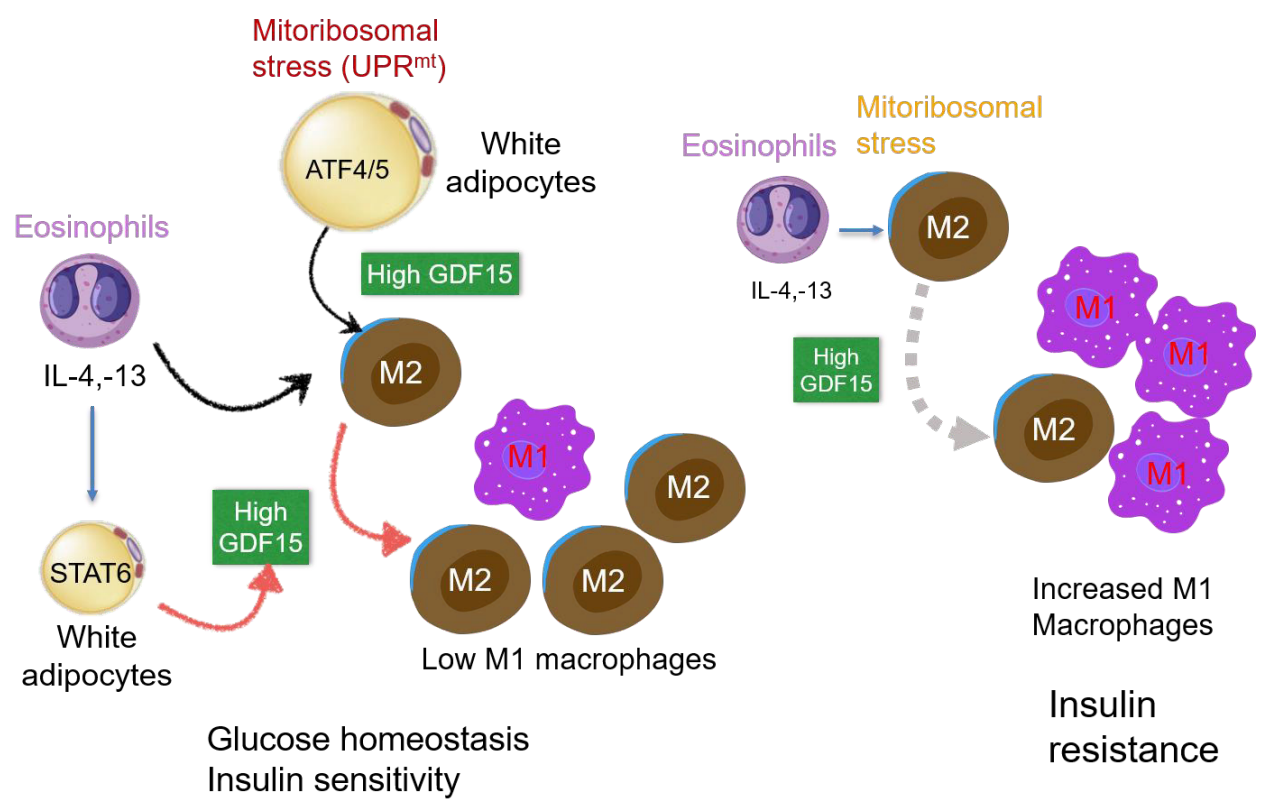

Fig. 3. Lessons from mitochondrial proteostasis in adipose tissue. Growth differentiation factor 15 (GDF15) is induced by cellular stress, including aging, inflammation, cancer, as well as mitochondrial dysfunction. Adipocyte mitoribosomal stress perturbs mitochondrial proteostasis, which upregulates the metabokine GDF15. GDF15 regulates macrophage polarization toward the M2-like state. M2-like macrophages are also induced by the Th2 cytokines, interleukin 4 (IL-4) and IL-13, which signal through the Janus kinase (JAK)-signal transducer and activator of transcription 6 (STAT6) pathway and lead to improvement of glucose homeostasis and insulin sensitivity. GDF15-deficient macrophages are prone to a M1-like phenotype, which is associated with adipose inflammation and systemic insulin resistance. Therefore, GDF15 has a beneficial effect on regulating macrophage polarization in adipose tissue, which is further associated with improvement of systemic metabolism. ATF, activating transcription factor; $\mathrm{UPR}^{\mathrm{mt}}$, mitochondrial unfolded protein response.

metabokines play an important role in the phenotype associated with OxPhos dysfunction in AdKO mouse adipocytes [32]. The anti-inflammatory effect of GDF 15 was extensively studied and discussed in the previous section $[67,68]$. However, the mechanism by which metabokines regulate systemic metabolism in tissue-specific mitochondrial dysfunction models is not fully understood.

We recently demonstrated that AdKO mice with whole-body GDF15 deletion have increased M1 macrophage proportions and reduced M2 macrophage expression in adipose tissue. Furthermore, we observed that myeloid-specific mitoribosomal defects induced M1 macrophage polarization and decreased M2 macrophages in adipose tissue [54]. It was also observed that M2 macrophage polarization by IL-4 treatment did not occur in macrophages of GDF15 KO mice, suggesting that GDF15 is a regulator of anti-inflammatory macrophage polarization, while also acting as a protective metabokine against WAT inflammation [54]. Adipose tissue inflammation is associated with dysregulated immune cell function and a high M1/M2 macrophage ratio, and is involved in systemic insulin resistance [69,70]. M2 macrophages are associated with Th2 cytokines, which are se- creted from eosinophils [71]. Th2 cells in adipose tissue suppress inflammatory responses by secreting the anti-inflammatory cytokine IL-10 [72]. IL-4 and IL-13, secreted from eosinophils in adipose tissue, are associated with macrophage reconstitution and are involved in improved glucose tolerance and insulin sensitivity [71]. We observed that GDF15 was required for IL-13-induced M2 macrophage polarization via the Janus kinase (JAK)-signal transducer and activator of transcription 6 (STAT6) pathway. It was shown that administration of IL-13 to wild-type mice fed an HFD improved glucose tolerance, which was not observed in GDF15 KO mice. These findings suggest that the improvement of systemic metabolism by IL-13, a Th2 cytokine, is mediated by GDF15 and acts as a regulator of antiinflammation and systemic glucose homeostasis (Fig. 3) [73].

The metabolic action of GDF15 was shown to regulate food intake and body weight through binding with GDNF family receptor alpha like (GFRAL), which is localized in the area postrema and the nucleus tractus solitarius region of the hindbrain [74-76]. Weight loss and food intake reduction were eliminated in GFRAL KO mice, suggesting that GDF15 has a central role in appetite regulation [74-76]. However, other studies suggested 


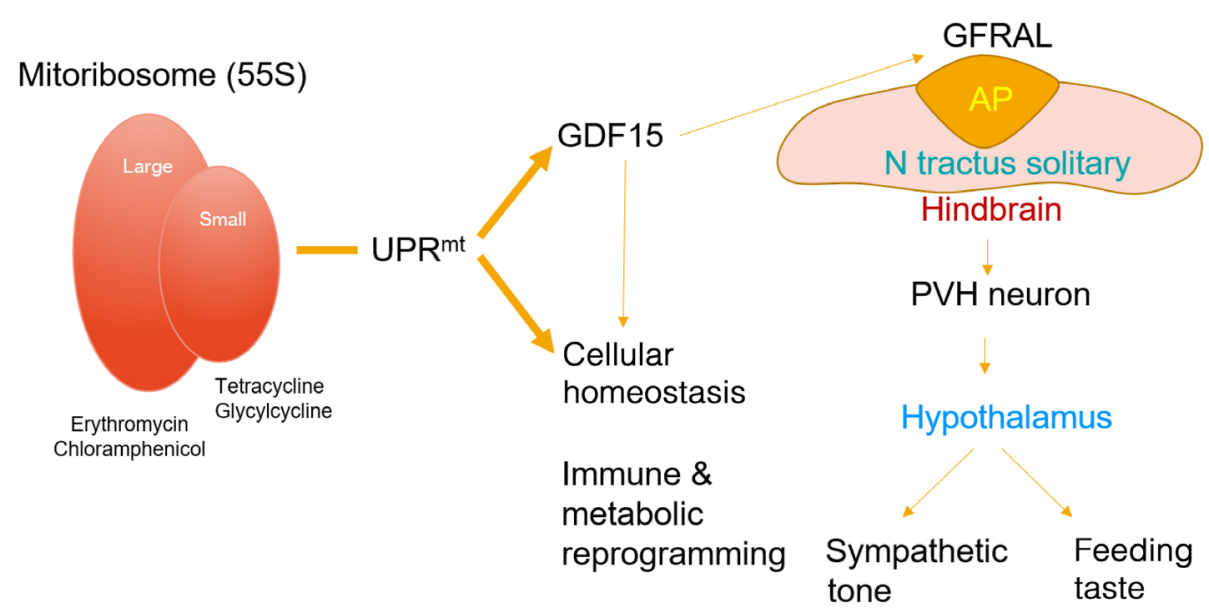

Fig. 4. Mitoribosomal stress couples the mitochondrial unfolded protein response (UPR $\left.{ }^{\mathrm{mt}}\right)$ to systemic energy metabolism. Upregulation of the $\mathrm{UPR}^{\mathrm{mt}}$ leads to cellular homeostasis with increased mitochondrial proteostasis, known as mitochondrial quality control. The UPR ${ }^{\mathrm{mt}}$ also induces growth differentiation factor 15 (GDF15), which binds to GDNF family receptor alpha like (GFRAL) in the area postrema (AP) and the nucleus tractus solitarius (NTS) region of the hindbrain. The GDF15-GFRAL axis acts as a regulator of the anorexigenic effect, resulting in the reduction of body weight. The peripheral action of GDF15 has been demonstrated in various studies, but its receptor in peripheral tissue has not yet been discovered. Therefore, further research is needed to confirm the mechanism of peripheral GDF15 action. PVH, paraventricular nucleus of the hypothalamus.

that GDF15 may have a peripheral action [77,78]. Thus, further studies of the peripheral receptor of GDF15 are necessary to identify its peripheral metabolic activity. Collectively, GDF15, is a metabokine that is increased by the mitochondrial stress response, and possibly plays a peripheral role in regulating intercellular homeostasis through not only central nervous systemmediated action via GFRAL, but also through immune and metabolic reprogramming through undiscovered receptors (Fig. 4).

\section{CONCLUSIONS}

GDF15 is highly increased in various pathologies including obesity, cancer, and mitochondrial stress. Whole-body KO of Gdf15 in mice showed increased weight gain due to higher food intake. An adipocyte-specific mitoribosomal defect mouse model (AdKO) showed dual activation of cell-autonomous (chaperones and proteases) and cell non-autonomous metabokine mechanisms in WAT. This finding implies a novel role for the UPR ${ }^{\mathrm{mt}}$ and metabokine secretion in adipose tissue homeostasis, which can regulate both systemic glucose homeostasis and EE as part of an organismal adaptation to local mitochondrial stress. We have shown that adipose OxPhos function from WAT can influence systemic glucose homeostasis and EE in pathologic states such as diet-induced obesity via the metabokine GDF15. Several studies have discovered that GDF15 plays a role in appetite regulation and body weight gain through its binding with GFRAL, but it is not known which receptors and mechanisms are involved to exert the peripheral effects of GDF15. Thus, further research is needed to discover the mode of action of GDF15 in peripheral tissues.

\section{CONFLICTS OF INTEREST}

No potential conflict of interest relevant to this article was reported.

\section{ACKNOWLEDGMENTS}

We apologize to the authors whose work was not included in this review. I, Minho Shong, would like to express my sincere gratitude to emeritus professor Hun Ki Min (Namgok) for giving me the prestigious Namgok Award. Minho Shong was funded by the Strategic Initiative Program funded by the Ministry of Science, ICT \& Future Planning (No. NRF-2017R1E1A1A01075126) and Chungnam National University Research Fund. This study was supported by the Basic Science Research Program through the National Research Foundation of Korea (NRF) funded by the Ministry of Education (NRF-2020R1I1A1A01071937). 


\section{ORCID}

Min Jeong Choi https://orcid.org/0000-0002-2513-3083

Minho Shong https://orcid.org/0000-0002-0247-7115

\section{REFERENCES}

1. Heinonen S, Buzkova J, Muniandy M, Kaksonen R, Ollikainen M, Ismail K, et al. Impaired mitochondrial biogenesis in adipose tissue in acquired obesity. Diabetes 2015;64: 3135-45.

2. Pagliarini DJ, Calvo SE, Chang B, Sheth SA, Vafai SB, Ong $\mathrm{SE}$, et al. A mitochondrial protein compendium elucidates complex I disease biology. Cell 2008;134:112-23.

3. Parikh VS, Morgan MM, Scott R, Clements LS, Butow RA. The mitochondrial genotype can influence nuclear gene expression in yeast. Science 1987;235:576-80.

4. Tian Y, Garcia G, Bian Q, Steffen KK, Joe L, Wolff S, et al. Mitochondrial stress induces chromatin reorganization to promote longevity and UPR(mt). Cell 2016;165:1197-208.

5. Durieux J, Wolff S, Dillin A. The cell-non-autonomous nature of electron transport chain-mediated longevity. Cell 2011;144:79-91.

6. Nargund AM, Fiorese CJ, Pellegrino MW, Deng P, Haynes $\mathrm{CM}$. Mitochondrial and nuclear accumulation of the transcription factor ATFS-1 promotes OXPHOS recovery during the UPR(mt). Mol Cell 2015;58:123-33.

7. Bhaskaran S, Pharaoh G, Ranjit R, Murphy A, Matsuzaki S, Nair BC, et al. Loss of mitochondrial protease ClpP protects mice from diet-induced obesity and insulin resistance. EMBO Rep 2018;19:e45009.

8. Lee HJ, Chung K, Lee H, Lee K, Lim JH, Song J. Downregulation of mitochondrial lon protease impairs mitochondrial function and causes hepatic insulin resistance in human liver SK-HEP-1 cells. Diabetologia 2011;54:1437-46.

9. Kim SJ, Kwon MC, Ryu MJ, Chung HK, Tadi S, Kim YK, et al. CRIF1 is essential for the synthesis and insertion of oxidative phosphorylation polypeptides in the mammalian mitochondrial membrane. Cell Metab 2012;16:274-83.

10. Chung HK, Ryu D, Kim KS, Chang JY, Kim YK, Yi HS, et al. Growth differentiation factor 15 is a myomitokine governing systemic energy homeostasis. J Cell Biol 2017;216: $149-65$.

11. Lackey DE, Olefsky JM. Regulation of metabolism by the innate immune system. Nat Rev Endocrinol 2016;12:15-28.

12. Cinti S, Mitchell G, Barbatelli G, Murano I, Ceresi E, Faloia

8 www.e-enm.org
E, et al. Adipocyte death defines macrophage localization and function in adipose tissue of obese mice and humans. J Lipid Res 2005;46:2347-55.

13. Odegaard JI, Chawla A. The immune system as a sensor of the metabolic state. Immunity 2013;38:644-54.

14. Anthony RM, Urban JF Jr, Alem F, Hamed HA, Rozo CT, Boucher JL, et al. Memory T(H)2 cells induce alternatively activated macrophages to mediate protection against nematode parasites. Nat Med 2006;12:955-60.

15. Lumeng CN, Bodzin JL, Saltiel AR. Obesity induces a phenotypic switch in adipose tissue macrophage polarization. J Clin Invest 2007;117:175-84.

16. Rodriguez-Prados JC, Traves PG, Cuenca J, Rico D, Aragones J, Martin-Sanz P, et al. Substrate fate in activated macrophages: a comparison between innate, classic, and alternative activation. J Immunol 2010;185:605-14.

17. De Pauw A, Tejerina S, Raes M, Keijer J, Arnould T. Mitochondrial (dys)function in adipocyte (de)differentiation and systemic metabolic alterations. Am J Pathol 2009;175:92739.

18. Duncan RE, Ahmadian M, Jaworski K, Sarkadi-Nagy E, Sul HS. Regulation of lipolysis in adipocytes. Annu Rev Nutr 2007;27:79-101.

19. Newsholme EA, Crabtree B. Substrate cycles in metabolic regulation and in heat generation. Biochem Soc Symp 1976: 61-109.

20. Curtis JM, Grimsrud PA, Wright WS, Xu X, Foncea RE, Graham DW, et al. Downregulation of adipose glutathione S-transferase A4 leads to increased protein carbonylation, oxidative stress, and mitochondrial dysfunction. Diabetes 2010;59:1132-42.

21. Gao CL, Zhu C, Zhao YP, Chen XH, Ji CB, Zhang CM, et al. Mitochondrial dysfunction is induced by high levels of glucose and free fatty acids in 3T3-L1 adipocytes. Mol Cell Endocrinol 2010;320:25-33.

22. Lin Y, Berg AH, Iyengar P, Lam TK, Giacca A, Combs TP, et al. The hyperglycemia-induced inflammatory response in adipocytes: the role of reactive oxygen species. J Biol Chem 2005;280:4617-26.

23. Houstis N, Rosen ED, Lander ES. Reactive oxygen species have a causal role in multiple forms of insulin resistance. Nature 2006;440:944-8.

24. Wilson-Fritch L, Nicoloro S, Chouinard M, Lazar MA, Chui PC, Leszyk J, et al. Mitochondrial remodeling in adipose tissue associated with obesity and treatment with rosiglitazone. J Clin Invest 2004;114:1281-9.

Copyright (C) 2021 Korean Endocrine Society 
25. Choo HJ, Kim JH, Kwon OB, Lee CS, Mun JY, Han SS, et al. Mitochondria are impaired in the adipocytes of type 2 diabetic mice. Diabetologia 2006;49:784-91.

26. Bogacka I, Ukropcova B, McNeil M, Gimble JM, Smith SR. Structural and functional consequences of mitochondrial biogenesis in human adipocytes in vitro. J Clin Endocrinol Metab 2005;90:6650-6.

27. Huh JY, Kim Y, Jeong J, Park J, Kim I, Huh KH, et al. Peroxiredoxin 3 is a key molecule regulating adipocyte oxidative stress, mitochondrial biogenesis, and adipokine expression. Antioxid Redox Signal 2012;16:229-43.

28. Okuno Y, Fukuhara A, Hashimoto E, Kobayashi H, Kobayashi S, Otsuki M, et al. Oxidative stress inhibits healthy adipose expansion through suppression of SREBF1-mediated lipogenic pathway. Diabetes 2018;67:1113-27.

29. Vernochet C, Damilano F, Mourier A, Bezy O, Mori MA, Smyth $\mathrm{G}$, et al. Adipose tissue mitochondrial dysfunction triggers a lipodystrophic syndrome with insulin resistance, hepatosteatosis, and cardiovascular complications. FASEB J 2014;28:4408-19.

30. Enguix N, Pardo R, Gonzalez A, Lopez VM, Simo R, Kralli A, et al. Mice lacking PGC-1 $\beta$ in adipose tissues reveal a dissociation between mitochondrial dysfunction and insulin resistance. Mol Metab 2013;2:215-26.

31. Vernochet C, Mourier A, Bezy O, Macotela Y, Boucher J, Rardin MJ, et al. Adipose-specific deletion of TFAM increases mitochondrial oxidation and protects mice against obesity and insulin resistance. Cell Metab 2012;16:765-76.

32. Choi MJ, Jung SB, Lee SE, Kang SG, Lee JH, Ryu MJ, et al. An adipocyte-specific defect in oxidative phosphorylation increases systemic energy expenditure and protects against diet-induced obesity in mouse models. Diabetologia 2020;63:837-52.

33. Kleiner S, Mepani RJ, Laznik D, Ye L, Jurczak MJ, Jornayvaz FR, et al. Development of insulin resistance in mice lacking PGC-1 $\alpha$ in adipose tissues. Proc Natl Acad Sci U S A 2012;109:9635-40.

34. Kusminski CM, Ghaben AL, Morley TS, Samms RJ, Adams AC, An Y, et al. A novel model of diabetic complications: adipocyte mitochondrial dysfunction triggers massive $\beta$-cell hyperplasia. Diabetes 2020;69:313-30.

35. Ost M, Igual Gil C, Coleman V, Keipert S, Efstathiou S, Vidic V, et al. Muscle-derived GDF15 drives diurnal anorexia and systemic metabolic remodeling during mitochondrial stress. EMBO Rep 2020;21:e48804.

36. Kim KH, Jeong YT, Oh H, Kim SH, Cho JM, Kim YN, et al. Autophagy deficiency leads to protection from obesity and insulin resistance by inducing Fgf21 as a mitokine. Nat Med 2013;19:83-92.

37. Conte M, Ostan R, Fabbri C, Santoro A, Guidarelli G, Vitale $\mathrm{G}$, et al. Human aging and longevity are characterized by high levels of mitokines. J Gerontol A Biol Sci Med Sci 2019;74:600-7.

38. Wu Y, Williams EG, Dubuis S, Mottis A, Jovaisaite V, Houten SM, et al. Multilayered genetic and omics dissection of mitochondrial activity in a mouse reference population. Cell 2014;158:1415-30.

39. Morrow RM, Picard M, Derbeneva O, Leipzig J, McManus MJ, Gouspillou G, et al. Mitochondrial energy deficiency leads to hyperproliferation of skeletal muscle mitochondria and enhanced insulin sensitivity. Proc Natl Acad Sci U S A 2017;114:2705-10.

40. Shao LW, Niu R, Liu Y. Neuropeptide signals cell non-autonomous mitochondrial unfolded protein response. Cell Res 2016;26:1182-96.

41. Berendzen KM, Durieux J, Shao LW, Tian Y, Kim HE, Wolff S, et al. Neuroendocrine coordination of mitochondrial stress signaling and proteostasis. Cell 2016;166:1553-63.

42. Tran T, Yang J, Gardner J, Xiong Y. GDF15 deficiency promotes high fat diet-induced obesity in mice. PLoS One 2018;13:e201584.

43. Chrysovergis K, Wang X, Kosak J, Lee SH, Kim JS, Foley JF, et al. NAG-1/GDF-15 prevents obesity by increasing thermogenesis, lipolysis and oxidative metabolism. Int $\mathrm{J}$ Obes (Lond) 2014;38:1555-64.

44. Zhang Y, Xie Y, Berglund ED, Coate KC, He TT, Katafuchi $\mathrm{T}$, et al. The starvation hormone, fibroblast growth factor-21, extends lifespan in mice. Elife 2012;1:e00065.

45. Fruhbeck G, Gomez-Ambrosi J, Muruzabal FJ, Burrell MA. The adipocyte: a model for integration of endocrine and metabolic signaling in energy metabolism regulation. Am J Physiol Endocrinol Metab 2001;280:E827-47.

46. Guzik TJ, Skiba DS, Touyz RM, Harrison DG. The role of infiltrating immune cells in dysfunctional adipose tissue. Cardiovasc Res 2017;113:1009-23.

47. Weisberg SP, McCann D, Desai M, Rosenbaum M, Leibel RL, Ferrante AW Jr. Obesity is associated with macrophage accumulation in adipose tissue. J Clin Invest 2003;112: 1796-808.

48. Xu H, Barnes GT, Yang Q, Tan G, Yang D, Chou CJ, et al. Chronic inflammation in fat plays a crucial role in the development of obesity-related insulin resistance. J Clin Invest 
2003; $112: 1821-30$

49. Fjeldborg K, Pedersen SB, Moller HJ, Christiansen T, Bennetzen M, Richelsen B. Human adipose tissue macrophages are enhanced but changed to an anti-inflammatory profile in obesity. J Immunol Res 2014;2014:309548.

50. Ramond E, Jamet A, Coureuil M, Charbit A. Pivotal role of mitochondria in macrophage response to bacterial pathogens. Front Immunol 2019;10:2461.

51. Vats D, Mukundan L, Odegaard JI, Zhang L, Smith KL, Morel CR, et al. Oxidative metabolism and PGC-1beta attenuate macrophage-mediated inflammation. Cell Metab 2006;4:13-24.

52. Palsson-McDermott EM, Curtis AM, Goel G, Lauterbach MA, Sheedy FJ, Gleeson LE, et al. Pyruvate kinase M2 regulates Hif- $1 \alpha$ activity and IL-1 $\beta$ induction and is a critical determinant of the warburg effect in LPS-activated macrophages. Cell Metab 2015;21:65-80.

53. Mounier R, Theret M, Arnold L, Cuvellier S, Bultot L, Goransson $\mathrm{O}$, et al. AMPK $\alpha 1$ regulates macrophage skewing at the time of resolution of inflammation during skeletal muscle regeneration. Cell Metab 2013;18:251-64.

54. Jung SB, Choi MJ, Ryu D, Yi HS, Lee SE, Chang JY, et al. Reduced oxidative capacity in macrophages results in systemic insulin resistance. Nat Commun 2018;9:1551.

55. Gordon S. Alternative activation of macrophages. Nat Rev Immunol 2003;3:23-35.

56. Odegaard JI, Ricardo-Gonzalez RR, Goforth MH, Morel CR, Subramanian V, Mukundan L, et al. Macrophage-specific PPARgamma controls alternative activation and improves insulin resistance. Nature 2007;447:1116-20.

57. Johnen H, Kuffner T, Brown DA, Wu BJ, Stocker R, Breit $\mathrm{SN}$. Increased expression of the TGF-b superfamily cytokine MIC-1/GDF15 protects ApoE(-/-) mice from the development of atherosclerosis. Cardiovasc Pathol 2012;21:499505.

58. Preusch MR, Baeuerle M, Albrecht C, Blessing E, Bischof M, Katus HA, et al. GDF-15 protects from macrophage accumulation in a mousemodel of advanced atherosclerosis. Eur J Med Res 2013;18:19.

59. Wang X, Chrysovergis K, Kosak J, Eling TE. Lower NLRP3 inflammasome activity in NAG-1 transgenic mice is linked to a resistance to obesity and increased insulin sensitivity. Obesity (Silver Spring) 2014;22:1256-63.

60. Geng L, Lam KSL, Xu A. The therapeutic potential of FGF21 in metabolic diseases: from bench to clinic. Nat Rev Endocrinol 2020;16:654-67.
61. Rochette L, Zeller M, Cottin Y, Vergely C. Insights into mechanisms of GDF15 and receptor GFRAL: therapeutic targets. Trends Endocrinol Metab 2020;31:939-51.

62. Modi A, Dwivedi S, Roy D, Khokhar M, Purohit P, Vishnoi $\mathrm{J}$, et al. Growth differentiation factor 15 and its role in carcinogenesis: an update. Growth Factors 2019;37:190-207.

63. Lehallier B, Gate D, Schaum N, Nanasi T, Lee SE, Yousef H, et al. Undulating changes in human plasma proteome profiles across the lifespan. Nat Med 2019;25:1843-50.

64. Wang X, Chrysovergis K, Kosak J, Kissling G, Streicker M, Moser G, et al. hNAG-1 increases lifespan by regulating energy metabolism and insulin/IGF-1/mTOR signaling. Aging (Albany NY) 2014;6:690-704.

65. Fujita Y, Taniguchi Y, Shinkai S, Tanaka M, Ito M. Secreted growth differentiation factor 15 as a potential biomarker for mitochondrial dysfunctions in aging and age-related disorders. Geriatr Gerontol Int 2016;16 Suppl 1:17-29.

66. Ding Q, Mracek T, Gonzalez-Muniesa P, Kos K, Wilding J, Trayhurn $\mathrm{P}$, et al. Identification of macrophage inhibitory cytokine-1 in adipose tissue and its secretion as an adipokine by human adipocytes. Endocrinology 2009;150:1688-96.

67. Breit SN, Johnen H, Cook AD, Tsai VW, Mohammad MG, Kuffner T, et al. The TGF- $\beta$ superfamily cytokine, MIC-1/ GDF15: a pleotrophic cytokine with roles in inflammation, cancer and metabolism. Growth Factors 2011;29:187-95.

68. Abulizi P, Loganathan N, Zhao D, Mele T, Zhang Y, Zwiep T, et al. Growth differentiation factor-15 deficiency augments inflammatory response and exacerbates septic heart and renal injury induced by lipopolysaccharide. Sci Rep 2017;7: 1037.

69. Berg AH, Scherer PE. Adipose tissue, inflammation, and cardiovascular disease. Circ Res 2005;96:939-49.

70. Nishimura S, Manabe I, Nagasaki M, Eto K, Yamashita H, Ohsugi M, et al. CD8+ effector T cells contribute to macrophage recruitment and adipose tissue inflammation in obesity. Nat Med 2009;15:914-20.

71. Wu D, Molofsky AB, Liang HE, Ricardo-Gonzalez RR, Jouihan HA, Bando JK, et al. Eosinophils sustain adipose alternatively activated macrophages associated with glucose homeostasis. Science 2011;332:243-7.

72. Feuerer M, Herrero L, Cipolletta D, Naaz A, Wong J, Nayer A, et al. Lean, but not obese, fat is enriched for a unique population of regulatory $\mathrm{T}$ cells that affect metabolic parameters. Nat Med 2009;15:930-9.

73. Lee SE, Kang SG, Choi MJ, Jung SB, Ryu MJ, Chung HK, et al. Growth differentiation factor 15 mediates systemic 
glucose regulatory action of T-helper type 2 cytokines. Diabetes 2017;66:2774-88.

74. Emmerson PJ, Wang F, Du Y, Liu Q, Pickard RT, Gonciarz MD, et al. The metabolic effects of GDF15 are mediated by the orphan receptor GFRAL. Nat Med 2017;23:1215-9.

75. Mullican SE, Lin-Schmidt X, Chin CN, Chavez JA, Furman JL, Armstrong AA, et al. GFRAL is the receptor for GDF15 and the ligand promotes weight loss in mice and nonhuman primates. Nat Med 2017;23:1150-7.

76. Yang L, Chang CC, Sun Z, Madsen D, Zhu H, Padkjaer SB, et al. GFRAL is the receptor for GDF15 and is required for the anti-obesity effects of the ligand. Nat Med 2017;23: 1158-66.

77. Chung HK, Kim JT, Kim HW, Kwon M, Kim SY, Shong M, et al. GDF15 deficiency exacerbates chronic alcohol- and carbon tetrachloride-induced liver injury. Sci Rep 2017;7: 17238 .

78. Moon JS, Goeminne LJE, Kim JT, Tian JW, Kim SH, Nga HT, et al. Growth differentiation factor 15 protects against the aging-mediated systemic inflammatory response in humans and mice. Aging Cell 2020;19:e13195. 